\title{
Factors Influencing Success of Wind-Diesel Hybrid Systems in Remote Alaska Communities: Results of an Informal Survey
}

\author{
Ginny Fay and Nataliya Udovyk
}

Technical Report

October 2011

Prepared by:

Ginny Fay and Nataliya Udovyk Institute of Social and Economic Research University of Alaska Anchorage 3211 Providence Dr Anchorage AK 99508

For information contact:

vfay@alaska.edu 907-786-5402

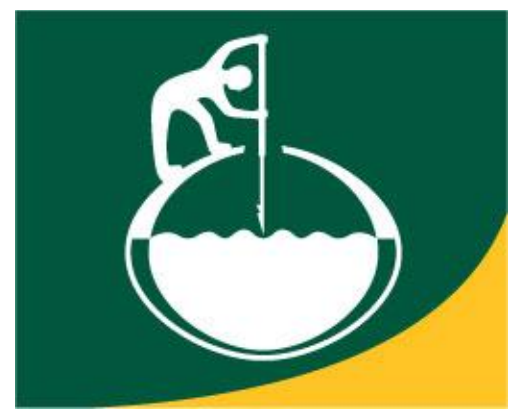


Table of Contents

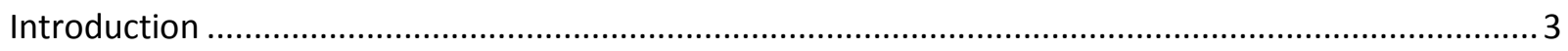

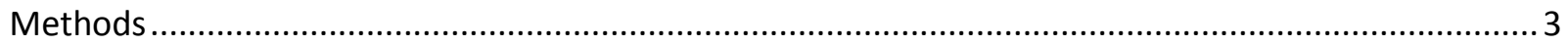

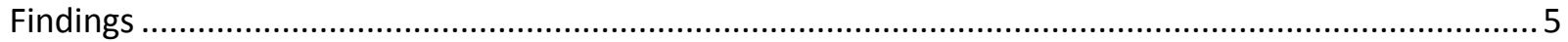

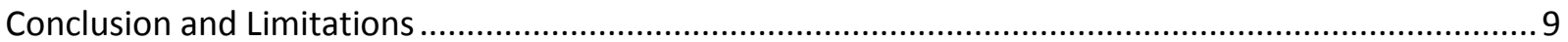

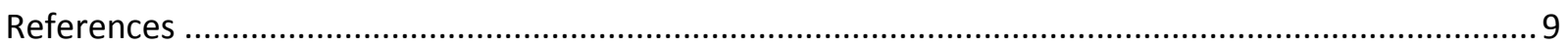

\section{Table of Figures}

Figure 1: Affiliations and number of individuals contacted ................................................................ 4

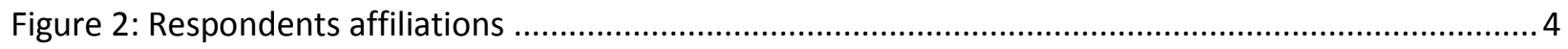

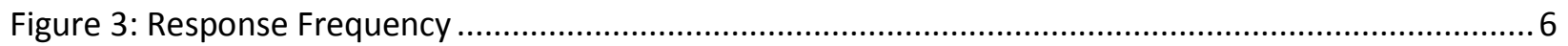

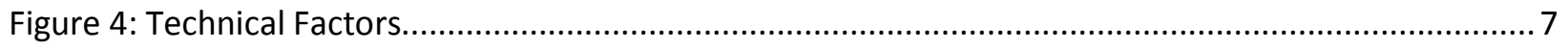

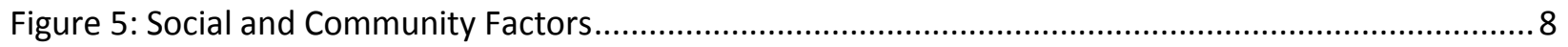

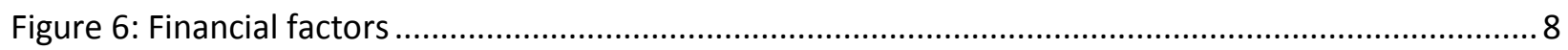

\section{Table of Tables}

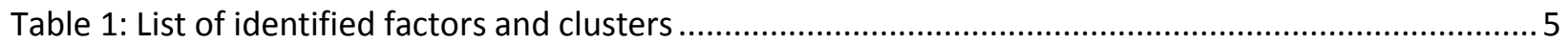

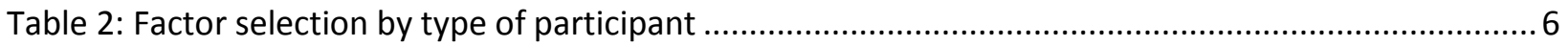

Suggested citation: Fay, Ginny and Nataliya Udovyk, 2011, Factors Influencing Success of Wind-Diesel Hybrid Systems in Remote Alaska Communities: Results of an Informal Survey, Institute of Social and Economic Research, University of Alaska Anchorage, 9 pp.

This research was supported by the U.S. Department of Energy, Making Wind Work for Alaska: Supporting the Development of Sustainable, Resilient, Cost-Effective Wind-Diesel Systems for Isolated Communities, EPSCoR project grant DE-PS02-09ER09-12. 


\section{Introduction}

In 2008 the Alaska State Legislature created and funded the Renewable Energy Fund. As a result of this available funding, the number of wind-diesel hybrid power systems is increasing dramatically in rural Alaska. Development, integration, and operation of complex wind technologies in remote, rural communities are challenging. With multiple communities in Alaska installing and operating these systems, it is important to understand the factors that influence successful completion, operation and long-term maintenance of projects (Fay, Schwoerer and Keith 2010; Colt, Goldsmith and Wiita 2003). As of fall 2011, over $\$ 107$ million has been spent constructing wind projects in 27 communities (Alaska Energy Authority 2011). The majority of these systems were built since 2008 and utilized $\$ 50.8$ million in appropriations from the REF by the Alaska legislature (Fay, Crimp and Villalobos-Melendez 2011)

This report summarizes the findings of an informal survey conducted on the most important characteristics of a successful wind-diesel hybrid power project in small remote rural communities. The survey was done to help guide socioeconomic research in Alaska on community capacity under a U.S. Department of Energy project entitled "Making Wind Work for Alaska: Supporting the Development of Sustainable, Resilient, Cost-Effective Wind-Diesel Systems for Isolated Communities".

\section{Methods}

Attendees of the Third International Wind-Diesel Workshop held March, 2011 in Girdwood, Alaska were asked to identify the three most important factors for success of a wind-diesel hybrid power system in a remote rural area. The group was comprised of Alaska, national and international participants including a number who traveled from Australia, Belgium, Canada, Denmark, and Russia ( $20 \%$ of survey participants). The participants had a variety of backgrounds including engineers, wind system developers, utility operators, community representatives, government agency employees, and entrepreneurs (Figure 1). The open-ended (?) question asked of all attendees was:

Please identify what in your experience are the three most important characteristics or ingredients of a successful wind diesel hybrid project in a small remote community. It can be technical components or community characteristics, or a combination of both.

Most of the participants were actively involved with the construction and operation of the wind-diesel projects in remote areas both in Alaska and other parts of the world.

The participants provided their responses via in-person and telephone interviews and e-mail. The inperson interviews were conducted during the workshop. As a result of insufficient time available to interview attendees, follow up contact was by email. Of the 162 people registered at the workshop, 97 people were contacted via e-mail, and 5 participants were interviewed. ${ }^{1}$ Of those contacted via e-mail, 36 responded via e-mail, 3 responded via telephone interview, and 58 did not respond. Based on the comments by a few who did not provide full responses, it may be that those who did not respond did not have direct experience developing or operating wind-diesel systems.

Each of the participants was asked to provide three factors in an open-ended response. Each response was given " 1 " frequency point. The responses were clustered into similar types driven by the responses. The responses clustered into technical/engineering, social/community and financial/leadership factors.

\footnotetext{
${ }^{1}$ All registrants were not contacted because they included university colleagues engaged in the same research project and partner agencies.
} 
Some participants listed more than three factors. In these cases, all the responses were given a frequency point. If a respondent repeatedly emphasized a given factor, it was given an additional frequency point in the data coding.

Figure 1: Affiliations and number of individuals contacted

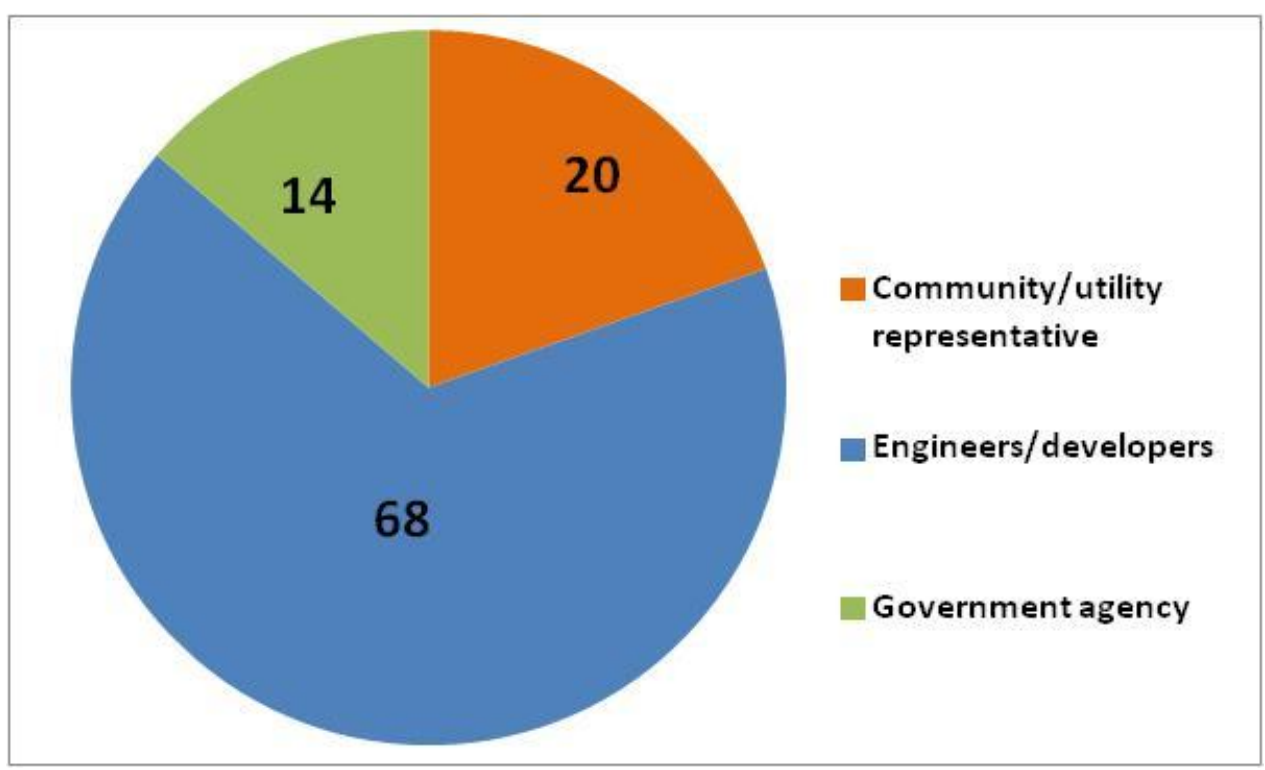

Majority of the respondents (34 individuals) had an industry-related and/or engineering background. Eight were government representatives and six came from community or local utility organizations (Figure 2). Affiliation characteristics of those that did not respond were similar to the response group. Derived from the participants' responses was a set of frequently cited factors. These were clustered into three major factor types: Technical, Social, and Financial/leadership (Table 1, Figure 3).

Figure 2: Respondents affiliations

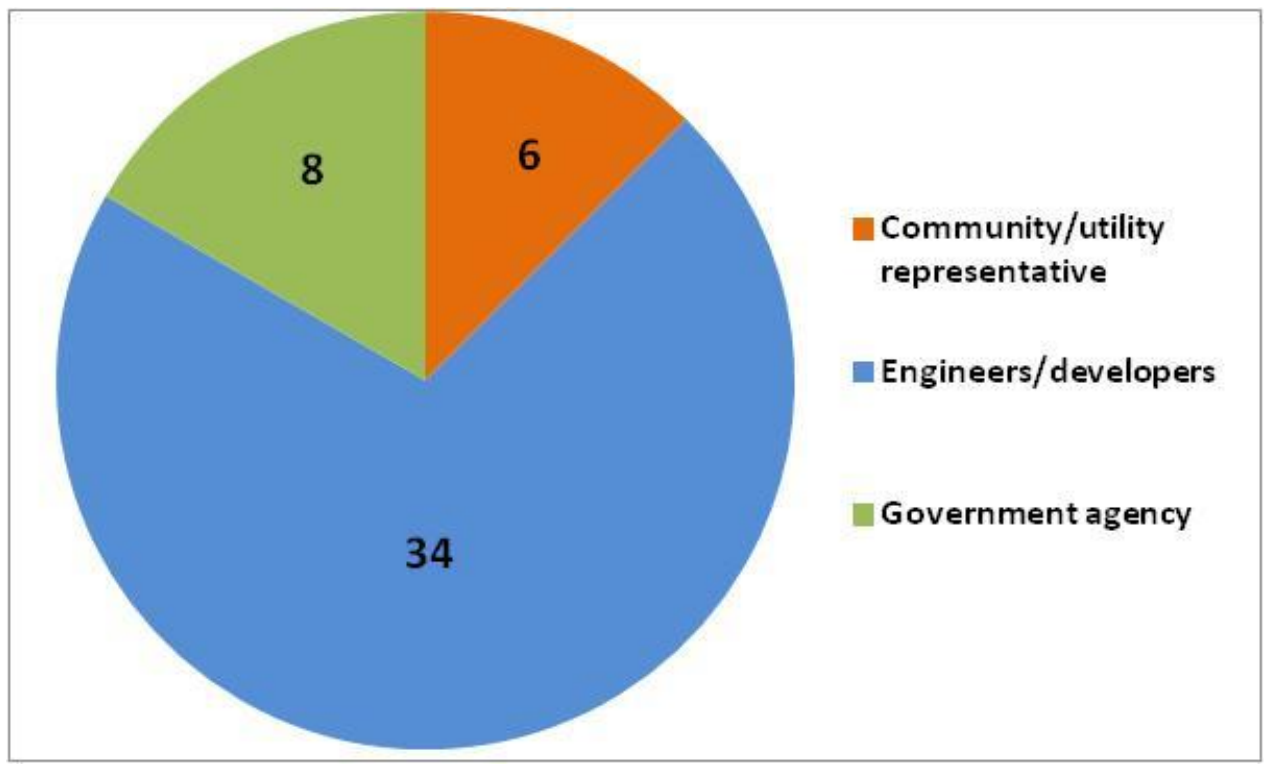


Technical

Reliable, robust, cost-efficient equipment

Adequate wind resource/proper siting to maximize production and minimize costs

System Integration

O\&M costs/long- term technical support

Professional, experienced engineers/developers

SCADA/Remote monitoring

Existing local infrastructure

Create new jobs/local income Local utility/operator participation

Community Commitment/ Participation/Support

Local work force training

Project champion/Leadership

Previous Mgmt/Construction experience
Financial/Leadership

Lowers fuel costs/usage

Comprehensive risk/economic analyses

Adequate financing/capital

Environmental/FAA permit facilitation

Well integrated billing, mgmt of utility

Leadership stability

Clear funding guidelines

Well maintained, operated diesel utility

Foundation/Subsurface conditions

No capital subsidies

Minimize noise/bird mortality

\section{Findings}

Despite the conference population being skewed towards technical engineering expertise, a significant number of success factors identified were non-engineering in nature (Figure 3). However, the majority of cited factors were technical, followed by social, and then financial and political/leadership factors (Figure 3). The average times a technical, social and financial factor was cited by participant type is shown in Table 2. 
Figure 3: Response Frequency

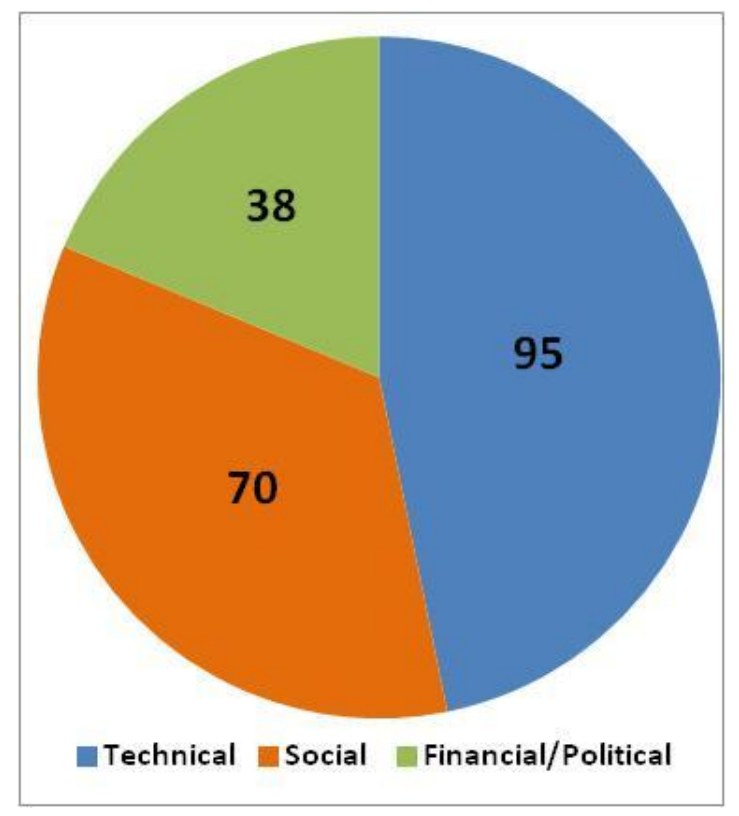

Table 2: Factor selection by type of participant

\begin{tabular}{|l|r|r|r|}
\hline & \multicolumn{3}{|c|}{ Average times factor cited: } \\
\hline Type of participant & Technical & Social & Financial \\
\hline Engineers/project developers & 1.9 & 1.4 & 0.8 \\
\hline Goverment agency & 2.4 & 1.4 & 0.9 \\
\hline Community/Utility & 1.7 & 2.0 & 0.5 \\
\hline
\end{tabular}

Of the technical factors, the most frequently mentioned fell under the grouping of "Reliable, robust, cost-efficient parts and equipment", and "Adequate wind resource/Proper siting to maximize production and minimize costs" (Figure 5). Constructing and maintaining wind projects in rural arctic Alaska require strenuous utilization of the equipment and parts due to the weather conditions. Turbine availability depends on the reliability and robustness of the parts and equipment. Capacity factors and energy production depend on wind resource availability, which are dependent on project location and siting. A robust wind resource contributes to higher energy production, lower energy costs and system long-term sustainability.

Other technical factors including "System integration," "O\&M costs/ long term technical support," and "Professional, experienced engineers and construction teams" all received nine points each. Their significance is directly connected with existing experience in operations of wind-diesel systems in rural areas. Both diesel generators and wind turbines have to be well integrated to provide for the most efficient energy output. The systems must be well maintained and properly installed to maximize availability and operate successfully at their full potential. 
Figure 4: Technical Factors

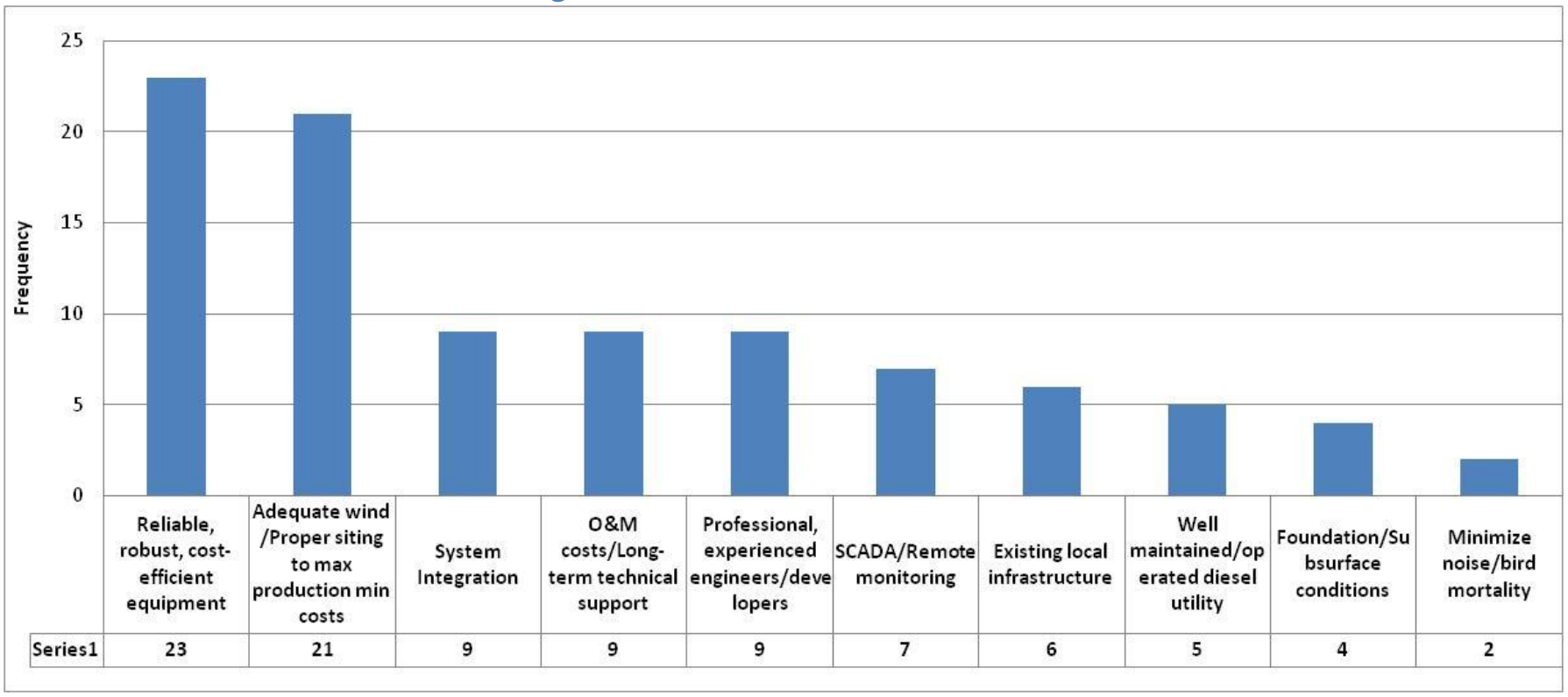

The "Social and Community" factors included "Community's commitment, participation and support of the project" being developed (Figure 5). A number of respondents commented that a community's interest in the project is a significant factor without which the long-term success cannot be accomplished. Respondents stressed that developers should approach projects with thoughts on how to best serve and educate the community about the project, not simply constructing the project without community input because the financial resources are available.

The second ranked social factor was local work-force training and development (19 points). Many rural utilities struggle to maintain skilled laborers, as the latter move to larger cities for better pay or other social reasons. In addition, wind-diesel systems are complicated, and require special training for operation and maintenance personnel either from the manufacturers or from the contractors involved with the project. Training local staff helps to build and develop local work-force and income.

Participation of the local utilities was also cited as a significant factor (11 points). Without utility participation and cooperation, it is to develop a project or convey its benefits to community members.

Among the financial and leadership factors, those attributed to successful project outcomes were "Lowers fuel costs/usage" (10 points) and "Comprehensive risk/economic analyses" (9 points). The measurement of the benefits by the wind-diesel projects result from fuel savings. In fact, it is the goal of such projects, to reduce the cost of energy for the rural residents through the displacement of expensive fossil fuels. 
Figure 5: Social and Community Factors

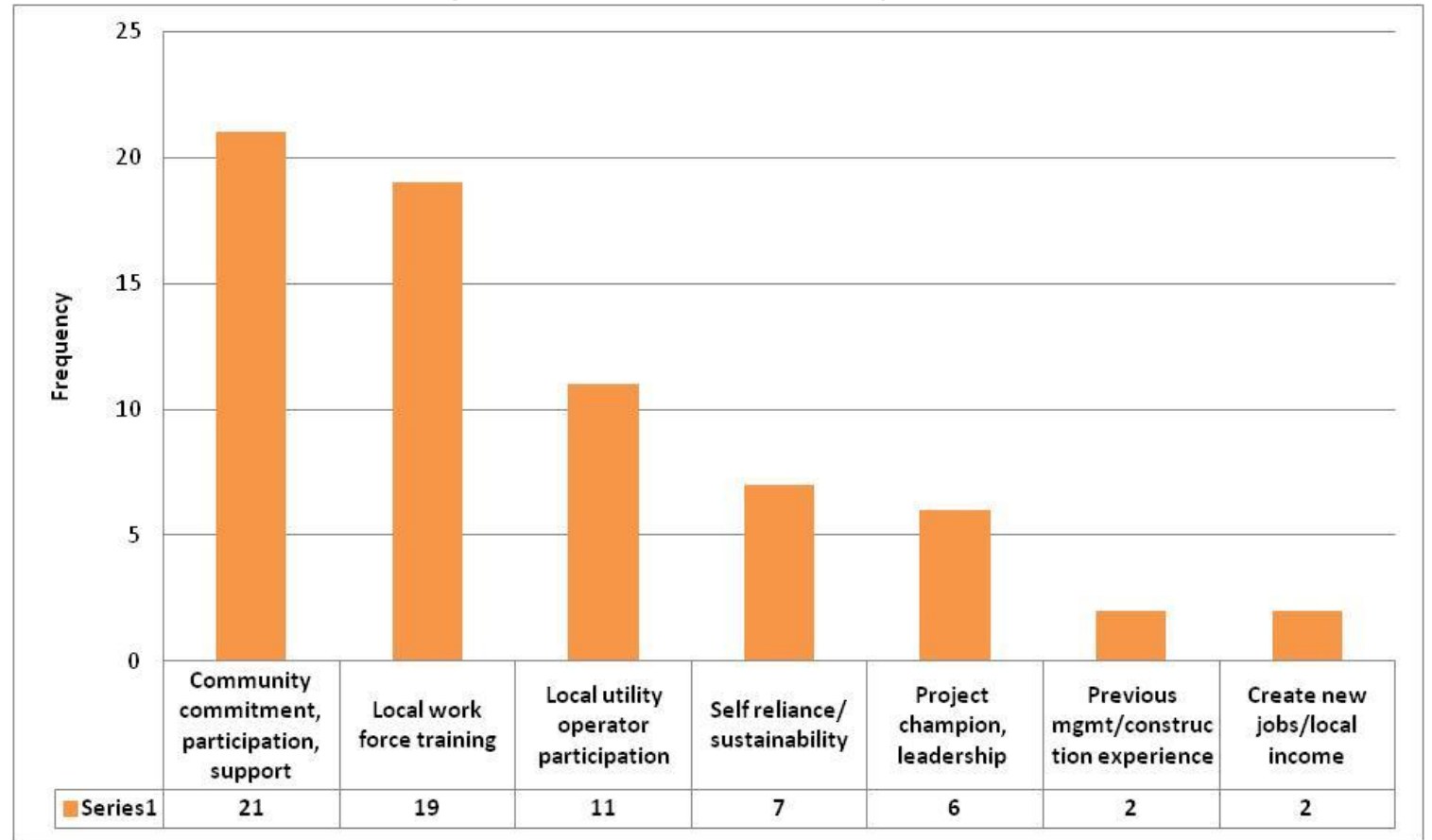

"Environmental and FAA Permits" (6 points) are essential for the project development. Without required permits, projects development can be halted, delayed or completely rejected.

Figure 6: Financial factors

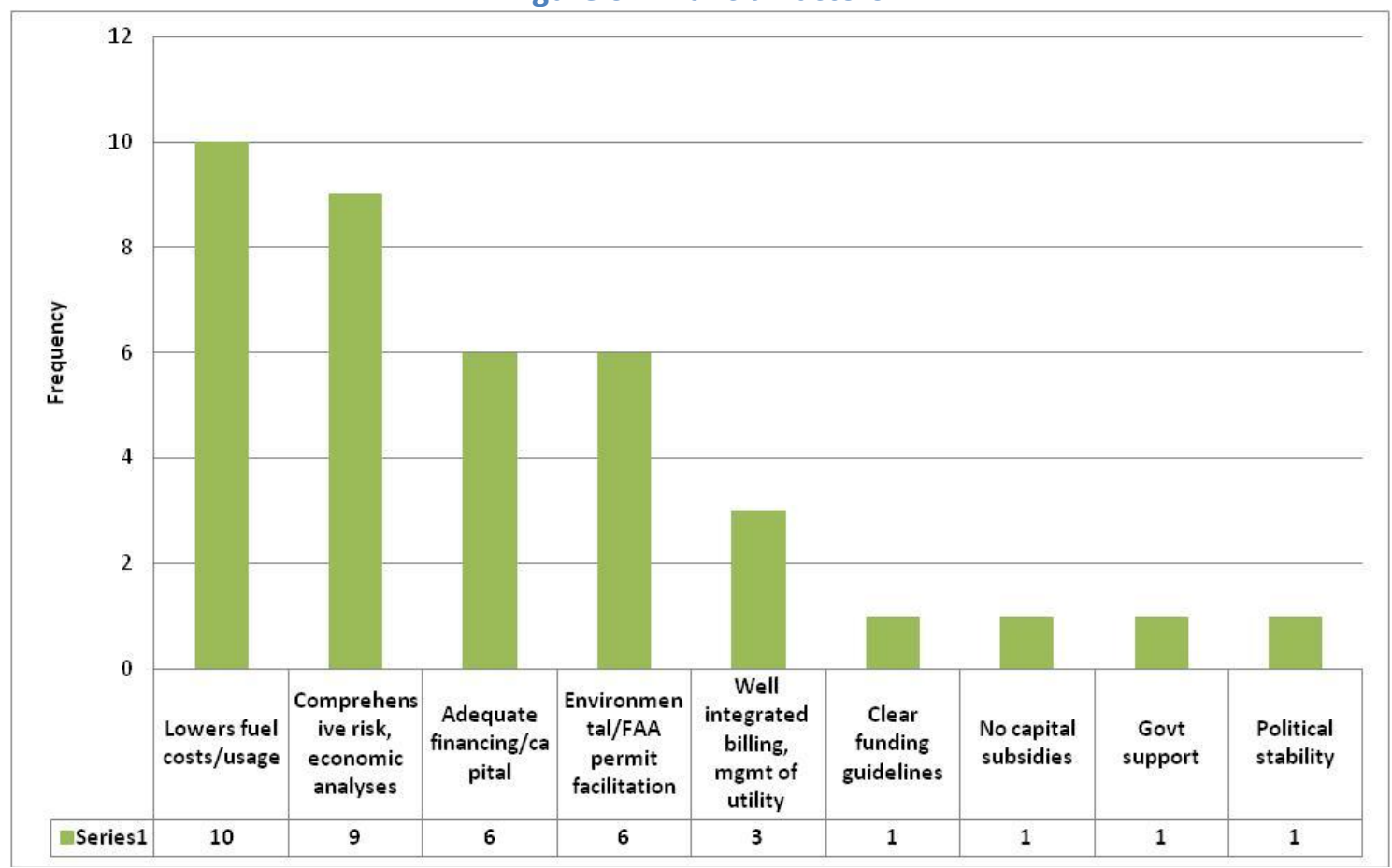




\section{Conclusion and Limitations}

The limitations of this analyses stems from the characteristic of the surveyed population. Since the majority of the respondents had technical/engineering background, it was likely that the majority of the emphasis of the "success factors" fell under technical factors.

Nevertheless, social factors such as "Community's commitment, participation and support of the project" and "Local work-force training" were cited as frequently as the highest ranking technical factors, indicating that technically inclined developers recognized the importance of community interests and factors being involved and addressed for successful project development and operation.

In addition, some of the financial and leadership factors such as "Risk analyses," "Lowering fuel costs," "Permitting," and "Adequate investment" were cited as frequently as technical factors, such as "Adequate wind resource,"" SCADA," "Existing local infrastructure", and "Well maintained power plant". This may show that, though finance and leadership may not be the highest ranking items on the success list of many individuals involved in wind-diesel system construction in rural Alaska, they exert strong influence on project outcomes.

\section{References}

Alaska Energy Authority, 2011, Wind Program data.

Colt, Steve, Scott Goldsmith, and Amy Wiita. Sustainable Utilities in Rural Alaska: Effective Management, Maintenance and Operation of Electric, Water, Sewer, Bulk Fuel, Solid Waste, Institute of Social and Economic Research, University of Alaska Anchorage, 2003.

Fay, G., P. Crimp, and A. Villalobos-Melendez, 2011, Alaska Renewable Energy Fund: How it Works and Lessons We've Learned, Technical Report, Institute of Social and Economic Research, University of Alaska Anchorage in collaboration with the Alaska Energy Authority, prepared for the 8th International Conference on Environmental, Cultural, Economic and Social Sustainability, forthcoming.

Fay, Ginny, Tobias Schwoerer, and Katherine Keith. Alaska Isolated Wind-Diesel Systems: Performance and Economic Analysis. Prepared for Alaska Energy Authority and Denali Commission, Institute of Social and Economic Research, University of Alaska Anchorage and Alaska Center for Energy and Power, University of Alaska Fairbanks, 2010. 